\title{
Advantages and challenges of stem cell therapy for osteoarthritis (Review)
}

\author{
STEPHANIE JYET QUAN LOO and NYET KUI WONG \\ Division of Applied Biomedical Sciences and Biotechnology, School of Health Sciences, \\ International Medical University, Kuala Lumpur 57000, Malaysia
}

Received January 25, 2021; Accepted April 12, 2021

DOI: $10.3892 /$ br.2021.1443

\begin{abstract}
Osteoarthritis (OA) is a degenerative disorder of the cartilage and is one of the leading causes of disability, particularly amongst the elderly, wherein patients with advanced-stage OA experience chronic pain and functional impairment of the limbs, thus resulting in a significantly reduced quality of life. The currently available treatments primarily revolve around symptom management, and is thus palliative rather than curative. The aim of the present review is to briefly discuss the limitations of some of the currently available treatments for patients with OA, and highlight the value of the potential use of stem cells in cellular therapy, which is widely regarded as the breakthrough that can address the present unmet medical needs for treatment of degenerative diseases, such as OA. The advantages of stem cell therapy, particularly mesenchymal stem cells, and the challenges involved are also discussed in this review.
\end{abstract}

\section{Contents}

1. Introduction

2. Challenges of conventional treatment methods for OA

3. Stem cell therapy

4. Types of MSC therapy for the treatment of OA

5. General advantages of MSCs over other types of stem cells for therapeutic purposes

6. MSC therapy offers analgesic, chondroprotective and regenerative properties when used for the treatment of OA

7. Challenges involved in the use of MSC therapy for OA

8. Conclusions

Correspondence to: Professor Nyet Kui Wong, Division of Applied Biomedical Sciences and Biotechnology, School of Health Sciences, International Medical University, Kuala Lumpur 57000, Malaysia E-mail: wongnyetkui@imu.edu.my

Key words: osteoarthritis, stem cell therapy, mesenchymal stem cells

\section{Introduction}

Arthritis is an umbrella term used to refer to diseases that cause pain and inflammation of the joints, and it characterized by painful inflammation and stiffness of the joints (1). Osteoarthritis (OA) is one of the most commonly diagnosed types of arthritis, and it is considered a chronic, debilitating and prevalent joint disease, accounting for $23 \%$ of all cases of musculoskeletal disorders, according to the Global Burden Disease study 2017 (2). In brief, OA occurs due to the loss of articular cartilage within the synovial joints with the natural propensity to occur in elderly individuals $(3,4)$. The high count of years lived with disability of patients with OA makes it one of the leading causes of disability, where patients with advanced-stage OA tend to experience chronic pain and functional impairment of the limbs, thus resulting in a poor quality of life (1).

Generally, a healthy joint possesses a layer of slippery tissue known as the articular cartilage, which is comprised primarily of chondrocytes and extracellular matrix (ECM). The ECM is predominantly made up of proteoglycan and type II collagen fiber (5). With several roles in the musculoskeletal system, the articular cartilage lubricates the bones during angular movements and absorbs shock to prevent the bones from impacting one another. This involves the spreading of the load evenly across the joints during weight-bearing activities (such as walking and weight-lifting), as well as high-intensity activities (such as running and jumping). Additionally, the articular cartilage also acts as a reservoir that stores synovial fluid; a fluid that transports nutrients to the joints (1).

Cartilage can be damaged through several factors, such as injuries as well as autoimmune diseases including rheumatoid arthritis (6). However, it can also be damaged from wear-and-tear over time. Typically, the occurrence of wear-and-tear are often counteracted by the repair and renewal of articular cartilage. However, the regenerative capacity is dependent on several aspects, including genetic background, age, sex, body weight and the level of physical activity an individual partakes in (7). When the cartilage damage outweighs the regenerative capacity of the body, thinning of the articular cartilage occurs followed by a progressive loss of articular cartilage. Under such circumstances, the individual will thus be diagnosed with OA (5). 
$\mathrm{OA}$ is also referred to as degenerative arthritis due to its tendency to develop as a person ages, as well as the fact that it is characterized by the loss of the cartilage that leads to constant friction followed by the eventual deformation of the bones $(1,8)$. In such events, the patient will experience inflammation and subsequently, pain and stiffness to the joints $(7,8)$. OA can affect any joint in the body, but often occurs in the knees, small joints of the fingers, lower back, neck and hips (9). Though it was typically accepted that it occurs as part of the aging process, there are other causes of OA including congenital bone deformities, joint overuse, traumatic injuries, obesity and genetic diseases, such as Paget's disease and diabetes $(7,10,11)$.

\section{Challenges of conventional treatment methods for OA}

The primary process that underlies the development of OA is the substantial degeneration of the structures within the articular cartilage, thus causing severe pain and reduced mobility. Unfortunately, the treatment options available for patients with $\mathrm{OA}$ are palliative measures rather than curative. Symptom management, with a focus on halting or slowing the progression of OA range from physical and nonsurgical therapies to surgery, including: i) Exercise programs for muscle strengthening and weight loss, and the use of supporting devices such as braces; ii) pharmacological interventions to alleviate pain; and iii) surgical interventions $(12,13)$. However, there are certain challenges and limitations to all of these approaches as discussed in the following subsections.

Physical measures. A basic attempt to treat OA involves the introduction of an exercise program to strengthen the muscles surrounding the affected joints, and to promote weight loss if required. With regards to knee $\mathrm{OA}$, where the knees act as the pillar of support to the human body, a study demonstrated the association between muscle weakness, particularly the quadriceps, and the development of knee OA (14). In addition to weak muscle strength, obesity which is suggested to be secondary to inactivity, is well-established to favor the development of knee OA through increased leverage, whereby the risk of knee $\mathrm{OA}$ is reported to increase by $36 \%$ with every 2 units of body mass index (BMI) gained, and the likelihood of developing knee OA by $4.2 x$ in individuals with a $\mathrm{BMI}>30 \mathrm{~kg} / \mathrm{m}^{2}(15,16)$. Hence, it was recommended that patients with OA increase the amount of exercise they do, such as weight lifting and strength training to increase muscle strength, as this has been proven to reduce pain and improve physical function, as well as aid in weight-loss (17-20). However, the pain and physical restrictions that come with OA often act as hurdles that keep OA patients from implementing and sustaining such activities. In addition, maintaining a healthy weight is another challenge faced by patients with OA, as it requires (often substantial) changes to their lifestyle, long term determination, and commitment to achieve noticeable results.

Use of braces. The general purpose of the braces is to provide support, as well as align and immobilize the area of the affected the joint (21). They prevent and correct deformities, thereby improving function and assisting in slowing the progression of the disease (22). There are several categories of braces available for various purposes. The unloader knee brace is used specifically for patients with OA to alleviate pain and improve physical function. Other categories of braces include the prophylactic knee brace, which is used to provide protection of the healthy knees against injuries during athletic activities; the patellofemoral knee brace which is used for anterior knee pain; and the functional knee brace is used to improve stability of an unstable knee in ligament injuries, such as a torn anterior cruciate ligament (ACL) or post-ACL reconstruction (22). Studies have reported that the use of braces has beneficial effects for patients with OA by reducing the pain they experience, improving the physical function of the affected joint, as well as delaying the need for surgical interventions $(23,24)$. However, despite the benefits of these braces, it is only able to provide short-term pain relief, and are inefficient for long-term management (25). Furthermore, the efficacy of the knee braces varies between patients with $\mathrm{OA}$; as indicated in certain studies, the use of braces lacks symptomatic relief, may fit poorly, and may cause discomfort when wearing the braces as well as skin irritation $(26,27)$.

Medication. The use of pharmacological treatments for OA is often considered as a supplement in cases of severe OA, following failure to relieve symptoms by non-pharmacological methods (28). Some of the drugs used are analgesics, such as acetaminophen and opioids, NSAIDs and COX-2 inhibitors (29). Although the complementary usage of drugs and non-pharmacological regimen has been shown to be most effective for pain management of OA, there are safety concerns regarding the adverse effects of the drugs on the human body, such as liver toxicity as well as renal, cardiovascular and gastrointestinal side effects (29).

Surgical intervention. Surgery is considered as the final resort, when both pharmacological and non-pharmacological regimens fail to relieve the symptoms in patients with severe OA, particularly when their joints have entered a state of severe damage, causing unbearable pain, as well as deterioration of function in the affected patient. The types of surgical treatments for OA include arthroscopic lavage and debridement, cartilage repair, osteotomies and joint arthroplasty (30). Arthroscopic lavage and debridement are often performed as an initial surgical option that entails the removal of fragments of the meniscus, loose cartilage or osteophytes, and shaving of rough cartilage, and has been shown to alleviate pain and improve physical function (31). However, it has been demonstrated in randomized controlled trials that arthroscopic surgery was no more effective than a placebo surgery for treating knee OA. In the early 2000's, two seminal studies by Kirkley et al (32) and Moseley et al (33), made an impact on the use of arthroscopy for OA, in which the authors reported that patients with OA who received arthroscopy lavage and debridement did not show any improvements in the pain score and physical functions compared with a placebo group who underwent a sham surgery, a group that received optimized therapy, and a group that underwent physical therapy. The publication of these two landmark studies was followed by the update of the guidelines for the treatment of OA by the United Kingdom's National Institute for Health and Care Excellence, which no longer recommends arthroscopy as a treatment for OA (1). 
The final resort for a patient with OA who has progressed to the most severe grade would be a total joint replacement. However, the procedure for joint replacements may cause unbearable pain and requires a long duration for rehabilitation. The adverse outcomes observed in patients who undergo total knee replacement surgery include myocardial infarction, infections and pulmonary embolism (34).

\section{Stem cell therapy}

The inconsistency of palliative treatments for OA highlight the need for a more reliable and curative approach that targets the root cause of OA; the degeneration of articular cartilage. Hence, the notion of stem cell therapy has galvanized intensive investigation into its potential use for treatment of OA, due to its regenerative properties. Owing to their excellent self-renewing capacity as well the ability to differentiate into $>200$ cell types, the use of stem cells in cellular therapy has ushered in an exciting new epoch for the fields of regenerative medicine with grounds for optimism to address the present unmet medical needs to treat a variety of degenerative diseases, including OA (35). At present, three types of stem cells are commonly studied with regard to stem cell therapy: Embryonic stem cells (ESCs), induced pluripotent stem cells (iPSCs), and adult stem cells, and these are discussed below.

ESCs. ESCs are considered to be totipotent stem cells derived from the fertilized zygote cell, wherein the embryo is usually 4-5 days old $(35,36)$. The use of embryonic stem cells has generated ethical concerns, particularly with regard to how they are obtained (37). Hence, it is restricted for use in biomedical research only, and is to date, illegal for use as a treatment of any diseases, as their remains a notable bone of contention over the considerable ethical issues that arise, given that an embryo must be aborted to obtain the ESCs $(37,38)$.

iPSCs. As one of the major revolutions in stem cell research, the identification and interest in research on iPSCs was spurred on by the ethical issues raised over the sourcing of ESCs $(39,40)$. iPSCs were first discovered in 2006 by Takahashi and Yamanaka (39) who successfully reprogrammed the terminally differentiated fibroblast to an iPSC via introduction of four transcription factors, the so called Yamanaka factors; Sox2, Oct3/4, Klf4 and c-Myc $(39,41)$. Similar to ESCs, iPSCs exhibit a high degree of pluripotency, with the additional benefit of circumventing the ethical concerns regarding the use of ESCs.

Despite its initial promise as a potential substitute for ESCs however, the transition to iPSC research for clinical applications highlighted several obstacles inherent to the use of iPSCs for cellular therapy, which includes genomic instability, immunogenicity, teratoma formation and clonal variations amongst iPSCs derived from the same donor cells, thus raising major concerns over the safety of their use clinically $(40,42,43)$.

Adult stem cells. Adult stem cells are usually found in differentiated cells of specific tissues after birth, and are further categorized into hematopoietic stem cells (HSCs) and mesenchymal stem cells (MSCs) (44). The regeneration of the damaged tissues using adult stem cells was greeted as a breakthrough in relatively recent years, and has exhibited encouraging outcomes when used for treatment of several chronic degenerative conditions, such as degenerative disc disease, Parkinson's disease and amyotrophic lateral sclerosis. Numerous studies have demonstrated the safety and efficacy of adult stem cells for the treatment of several diseases (45-47).

HSCs. HSCs are the building blocks for the production of blood cells, including the erythrocyte and leukocyte lineages, as well as platelets $(48,49)$. HSCs are found in the bone marrow and the umbilical cord, and are now primarily used for the treatment of the majority of disorders of blood cells, including primary immune deficiencies, congenital cytopenia, and storage and metabolic disorders $(50,51)$. The transplantation of HSCs has been shown to ameliorate bone lesions, a decline in cognitive and central nervous function, as well as improving the survival of children diagnosed with Hurler's syndrome (the most severe form of mucopolysaccharidoses) (52). Furthermore, the use of HSCs has been deemed to be curative in the treatment of sickle cell diseases (53). There have been attempts to assess the efficacy of HSCs for the treatment of OA, wherein a study by Abdelmoaty et al (54) showed that patients who received repeated injections of autologous peripheral blood stem cells experienced improvements in physical function as well as improved articular cartilage quality. At present, the only FDA-approved stem cell products consist of hematopoietic progenitor cells that are derived from umbilical cord blood, solely for the treatment of blood disorders involving the hematopoietic system (55).

MSCs. MSCs are multipotent stem cells that are found ubiquitously throughout the musculoskeletal system in the human body, and can differentiate into various cell types including, but not limited to, osteoblasts, chondrocytes, adipocytes, astrocytes and cardiomyocytes (56-61). They can be isolated from the HSCs based on their ability to adhere readily to the plastic surfaces of tissue culture plates (56). MSCs can be derived from various tissues in the body, including bone marrow, adipose tissue, synovium, umbilical cord blood, dental pulp, amniotic fluid, dermis and peripheral blood (62-67). The characterization of MSCs are defined based on a guideline proposed by the International Society for Cellular Therapy (ISCT); the minimum criteria being that cells exhibit expression of specific markers, including CD44, CD90 and CD105, but lack expression of CD34, DC45 and CD133, as these are markers of HSCs (68). The revelation of the intrinsic nature of MSCs to regenerate and differentiate into chondrocytes has increased interest in the investigation of MSCs, and they show potential as an excellent alternative treatment option for OA. One study that used bone marrow aspirates in treating knee OA has successfully entered clinical trial phase 4, and was registered in ClinicalTrials.gov (Identifier, NCT03289416). In this clinical trial, undifferentiated cells found in the bone marrow aspirate concentrate (BMA) were shown to promote healing of damaged tissue, and aid in growth, repair and tissue regeneration. Whereas the full benefits of BMA remain to be elucidated, studies have shown that this treatment can relieve pain, and improve healing in articular cartilage and bone grafts (69). Although MSCs can be derived from numerous tissues in the body as mentioned previously, the two types of 
MSCs that are widely studied for the treatment of OA are bone marrow-derived MSCs (BMSCs) and adipose-derived stem cells (ASCs) $(70,71)$.

\section{Types of MSC therapy for the treatment of OA}

BMSCs. BMSCs are a population of fibroblast-like cells that reside in the stroma of the bone marrow (66). These MSCs were initially isolated from the bone marrow aspirate of the iliac crest, before the subsequent emergence of MSCs derived from other tissues, such as adipose tissue, umbilical cord and amniotic fluid $(72,73)$. Currently, BMSCs are regarded as the gold standard and remain the most frequently investigated cell type, as they are hypothesized to possess higher potential for chondrogenic differentiation (70). There are 58 registered clinical trials in Clinicaltrials.gov (as of March 2021), on the use of BMSCs for treatment of osteoarthritis using the key words 'osteoarthritis' and 'bone marrow stem cells'. However, only a handful of studies have been completed and have published their results (74-81).

ASCs. ASCs are stem cells isolated from adipose tissues. They were first identified as an MSC in 2001 (82), following which, they have been widely studied for their potential therapeutic value in regenerative medicine and tissue engineering $(63,83-85)$. Although ASCs exhibit similarities to the BMSCs, there are several distinct characteristics between these 2 types of stem cells, such as their differentiation potential and the complement of cell surface markers. BMSCs express CD106 (a marker that is involved in MSCs-mediated immunosuppression and the binding of hematopoietic progenitor cells) which was found to be absent on ASCs $(86,87)$ and the ASCs express CD49d ( $\alpha 4$ integrin that is involved in facilitating leukocyte migration) which was not detected on BMSCs (86). Unlike BMSCs, ASCs can be obtained in high yields from adipose tissues, which can be found abundantly in the body (84). It has been estimated that MSCs account for $0.001-0.004 \%$ of the bone marrow aspirate cells, whereas ASCs account for $\sim 2 \%$ of the lipoaspirate cells (84). The isolation of ASCs can be performed via liposuction aspirates or from subcutaneous adipose tissue fragments, and is less invasive compared to BMSCs (63). As of March 2021, 52 registered clinical studies were found on Clinicaltrials.gov using the key words 'osteoarthritis' and 'adipose stem cells'.

\section{General advantages of MSCs over other types of stem cells for therapeutic purposes}

MSCs are favored over the other types of stem cells, as they exhibit numerous advantages for therapeutic purposes, such as their relative abundance, ease of isolation, their multilineage differential potential, lower risk of malignant transformation, immunomodulatory properties and the lack of ethical issues.

Abundance and ease of isolation. Previous reports have suggested that MSCs originate from the perivascular niche, thus making it possible to isolate them from various tissues in the body such as bone marrow, adipose tissue, peripheral blood, the placenta and the umbilical cord $(72,73)$. However, the bone marrow and subcutaneous adipose tissues remain the preferential sources of obtaining MSCs, due to their relative abundance in the human body, particularly in the subcutaneous adipose tissue (88).

Multilineage differential potential. MSCs can be differentiated into various cell lineages. Over the years, in addition to the production of osteocytes, chondrocytes and adipocytes from MSCs, studies have also successfully induced MSCs to differentiate into oligodendrocytes (89-91), insulin-producing cells $(71,92,93)$ and cardiomyocytes (94), highlighting their potential for the treatment of various degenerative diseases, including diabetes mellitus (95), cardiovascular diseases $(96,97)$ and bone diseases $(98)$.

Lower risk of malignant transformation. MSCs are endogenously programmed to exhibit limited proliferation capacity in cultures, after which cells enter a state of senescence, preventing their ability to divide; this is termed the 'Hayflick limit' (99). Senescence is defined as a stress response that results in the arrest of cell proliferation, thus preventing the propagation of damaged cells and lowering the risk of malignant transformation in the body (100).

Immunomodulatory properties. Another characteristic of MSCs that contributes to the advantage of using MSCs is that they have been shown to exhibit immunomodulatory properties, wherein they secrete anti-inflammatory cytokines to suppress both the adaptive and innate immune responses, thus permitting their use as universal donor cells without the need for immunosuppressants (101-103). This is due to the presence of unique surface markers that permit the MSCs to remain undetected by the immune system, including the lack of expression of major histocompatibility complex class II and co-stimulatory cluster of differentiation (CD) molecules such as CD40 ligand, CD40, CD80 and CD86 (104-107). This highlights the possibility for the use of allogeneic MSCs to treat patients who do not meet the criteria for autologous stem cell therapy.

Lack of ethical issues. Unlike ESCs, MSCs can be derived from various tissues in the body and hence, the ethical concerns associated with ESCs do not apply to MSCs. Although ESCs have received significant interest due to their high-degree of pluripotency, the use of ESCs in clinical applications remains controversial due to the safety concerns over teratoma formation, as well as the ethical issues with regard to sourcing $(108,109)$.

\section{MSC therapy offers analgesic, chondroprotective and regenerative properties when used for the treatment of $\mathrm{OA}$}

Studies on MSC therapy for OA that have been performed globally to evaluate their safety and efficacy, ranging from proof-of-concept studies to randomized controlled clinical trials, and have yielded positive results. Additionally, there are no studies showing notable side effects of the use of BMSCs and ASCs, and they have seen progressive improvements when used to reduce pain, physical function, stabilization of cartilage defects and even the thickening of articular cartilage in patients with OA. Table I summarizes the randomized controlled trials of BMSCs and ASCs as a treatment for OA performed between 


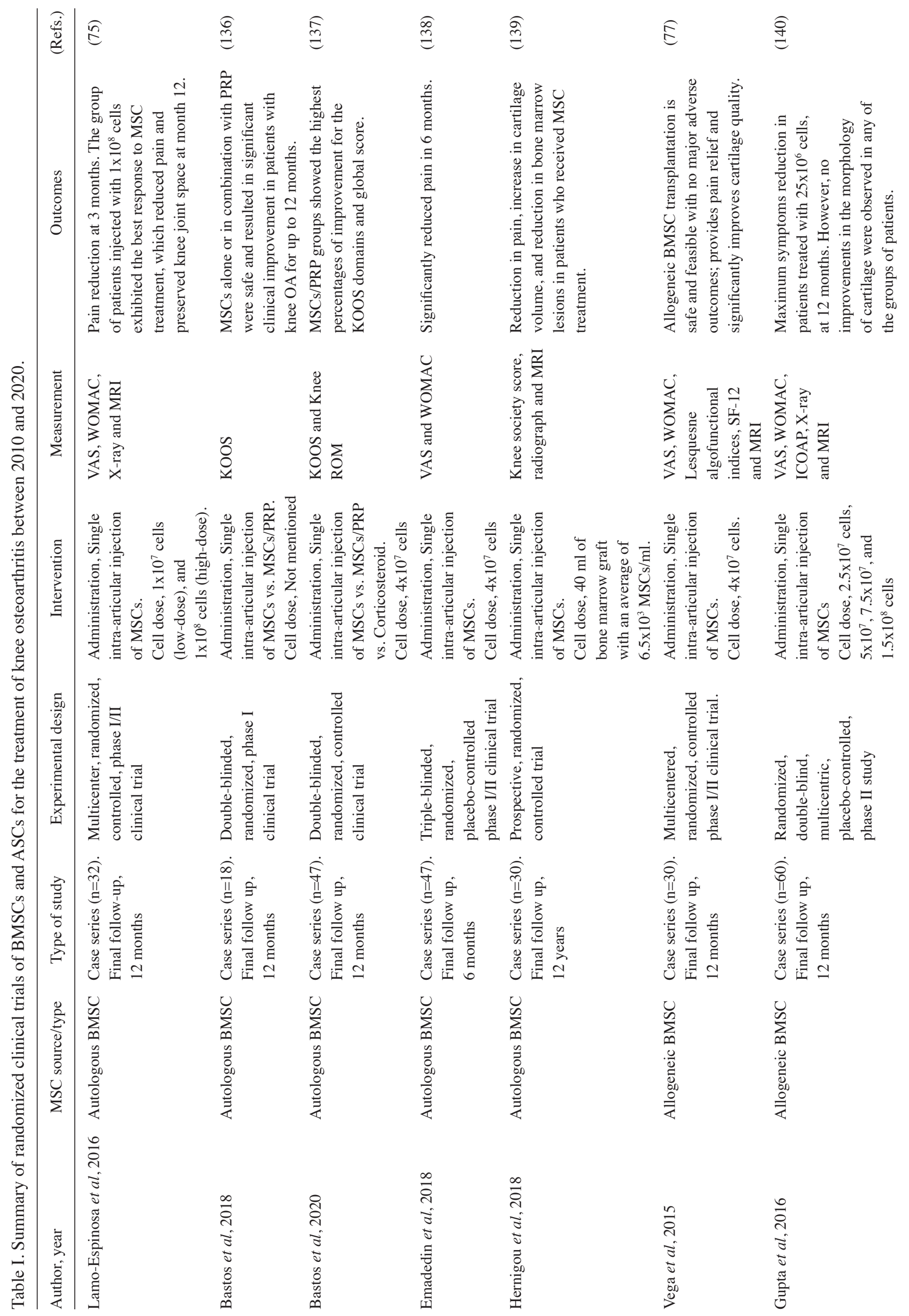




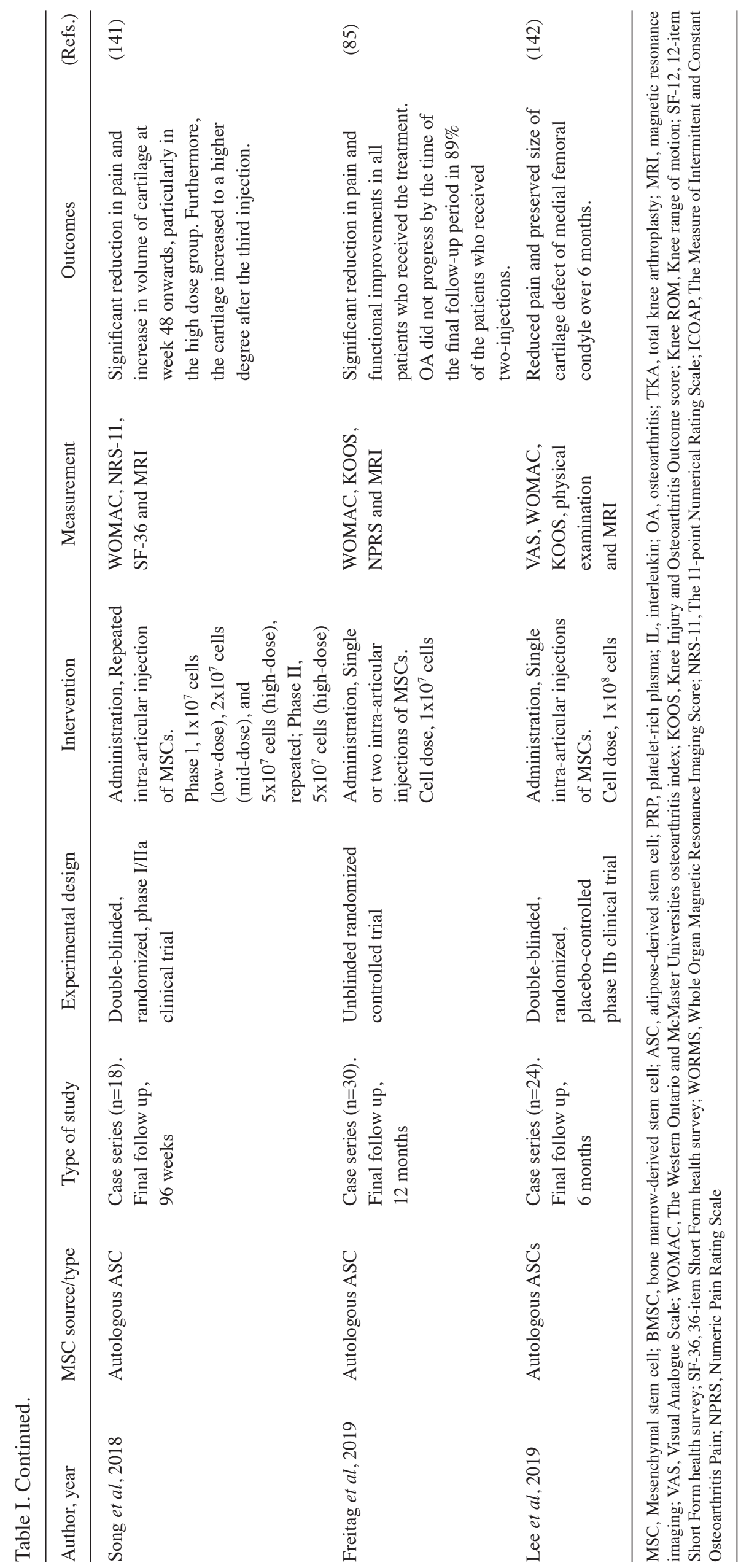




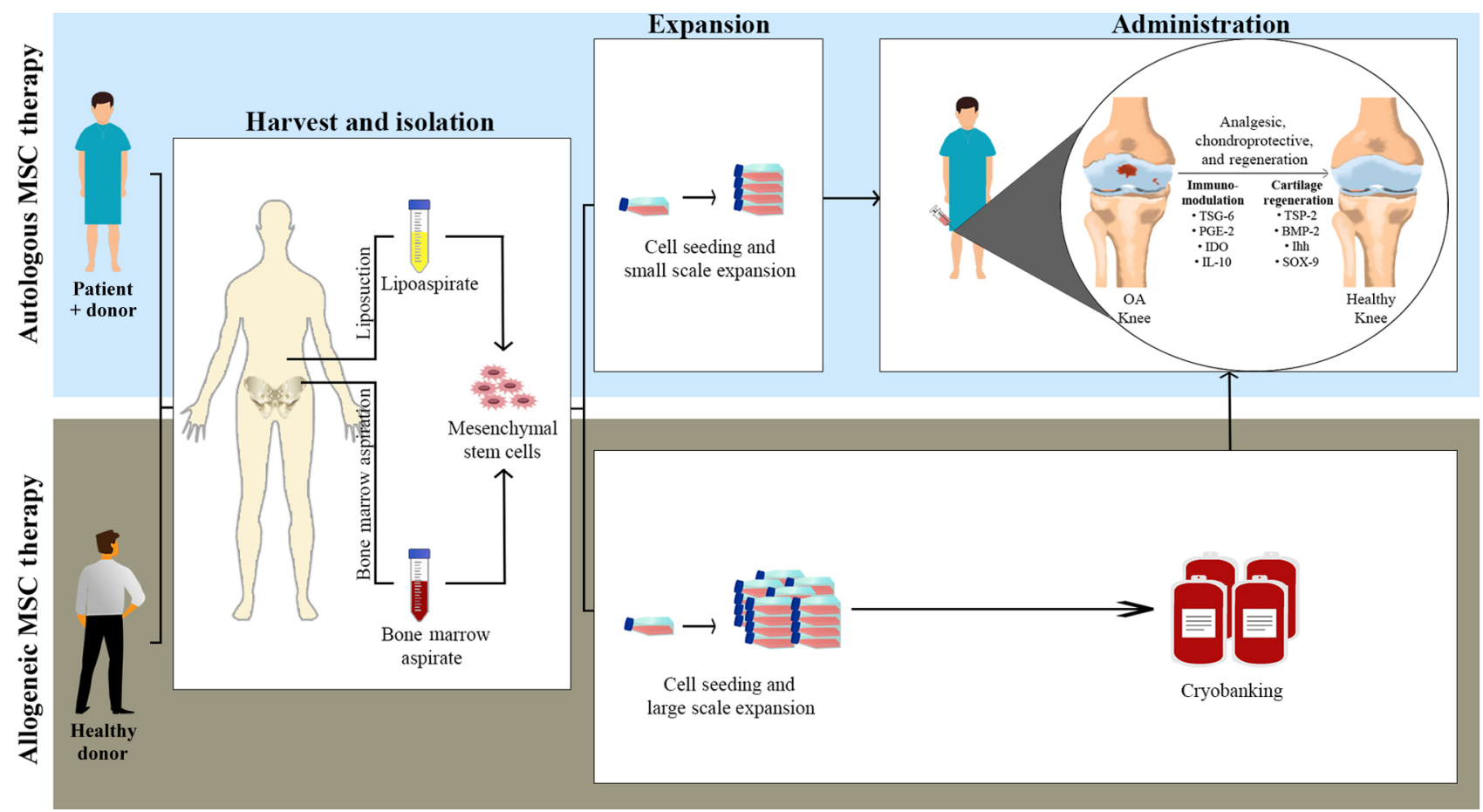

Figure 1. General procedures in using BMSCs and ASCs for the treatment of OA. Autologous MSCs are isolated from the patient's own tissue, whereas allogeneic MSCs are isolated from a healthy donor who is not a patient. The BMSCs and ASCs are harvested via bone marrow aspiration and liposuction, respectively, followed by the isolation of MSCs. The expansion of MSCs is performed on a small scale for autologous MSCs and large scale for allogeneic MSCs, and the latter are stored in a cryobank, to be later administered to patients with OA when required. MSCs are administered to the patients via intra-articular injection, and the expected beneficial outcomes post-treatment are analgesia, chondroprotective effects and cartilage regeneration. MSC, mesenchymal stem cell; BMSC, bone marrow-derived stem cells; ASC, adipose-derived stem cells; OA, osteoarthritis.

2010 and 2020. The general procedures used are as shown in Fig. 1. Collectively, the studies highlight their beneficial properties, exhibiting analgesic, chondroprotective and anatomical regenerative properties.

Analgesic and chondroprotective effects. Although the specific molecular mechanisms by which MSCs exert an analgesic effect remain to be elucidated, it is hypothesized that they revolve around its immunomodulatory effects, by inducing the synthesis of anti-inflammatory cytokines, such as IL-10, and downregulating the production of pro-inflammatory cytokines, such as IL-1, IL-6, TNF $\alpha$ and interferon (IFN)- $\gamma$ (110-114). MSCs are able to secrete numerous soluble growth factors and cytokines, including $\mathrm{TNF} \alpha$-stimulated gene/protein 6 (TSG-6), prostaglandin E2 (PGE-2) and indoleamine 2,3-dioxygenase (IDO), which contribute to their ability to mitigate pain $(103,115-117)$. It has been shown that the presence of MSCs results in the production of TSG-6, leading to inhibition of the toll-like receptors-2/nuclear factor $\kappa$-light-chain-enhancer of activated B cells signaling pathway, followed by the subsequent downregulation of inflammatory mediators, such as nitric oxide, TNF $\alpha$ and IL-1 $(103,115)$. Upregulation of PGE-2 by MSCs leads to inhibition of the IFN- $\gamma$, inducing the differentiation of M1-type macrophages to M2-type macrophages (116). Similarly, the production of IDO by MSCs also promotes the conversion of M1 macrophages to M2 macrophages (117).

The homing migratory ability of MSCs to sites of injury and inflammation provides beneficial relief in both BMSC and saline-treated knee in patients with bilateral OA (118-120).
Chondrocyte regenerative effect. The regenerative effect of MSCs on the cartilage has been shown to involve the high expression of several genes responsible for inducing chondrogenesis, and the subsequent development of normal cartilage. These genes include the production of thrombospondin-2, which promotes the Notch signaling pathway; the production of bone morphogenetic protein 2, which induces the SMAD signaling pathway; and the Indian hedgehog signaling pathway, which promotes the expression of SOX9 followed by increased expression of the Col2al gene, thus stimulating the production of proteoglycans and type II collagen, all of which are involved in cartilage regeneration (121-123). The likely mechanism by which MSCs exert their anti-inflammatory and cartilage regenerative effects is summarized in Fig. 2.

Several studies have highlighted the analgesic effects of MSCs is addition to their cartilage regenerative effects; however, follow-up is usually limited to 6-12 months post-treatment. The long-term potential of MSC therapy may thus be underrated, as the structural changes required for a prominent effect take at least a year to occur $(79,124)$.

In general, numerous reports have shown that as little as a single injection of a $1 \times 10^{6}$ cell dose is sufficient for initiation of their analgesic effects, although eliciting chondrocyte regeneration response in cartilage requires a much higher dose of at least $1 \times 10^{8}$ cells $(81,125)$. Hence, higher quality randomized, controlled clinical studies with larger cohorts are required to strengthen the evidence and evaluate the quality of its therapeutic outcomes. Additionally, established protocols for consideration of the optimal dose, time of intervention, method of delivery and safety precautions also require extensive study. 


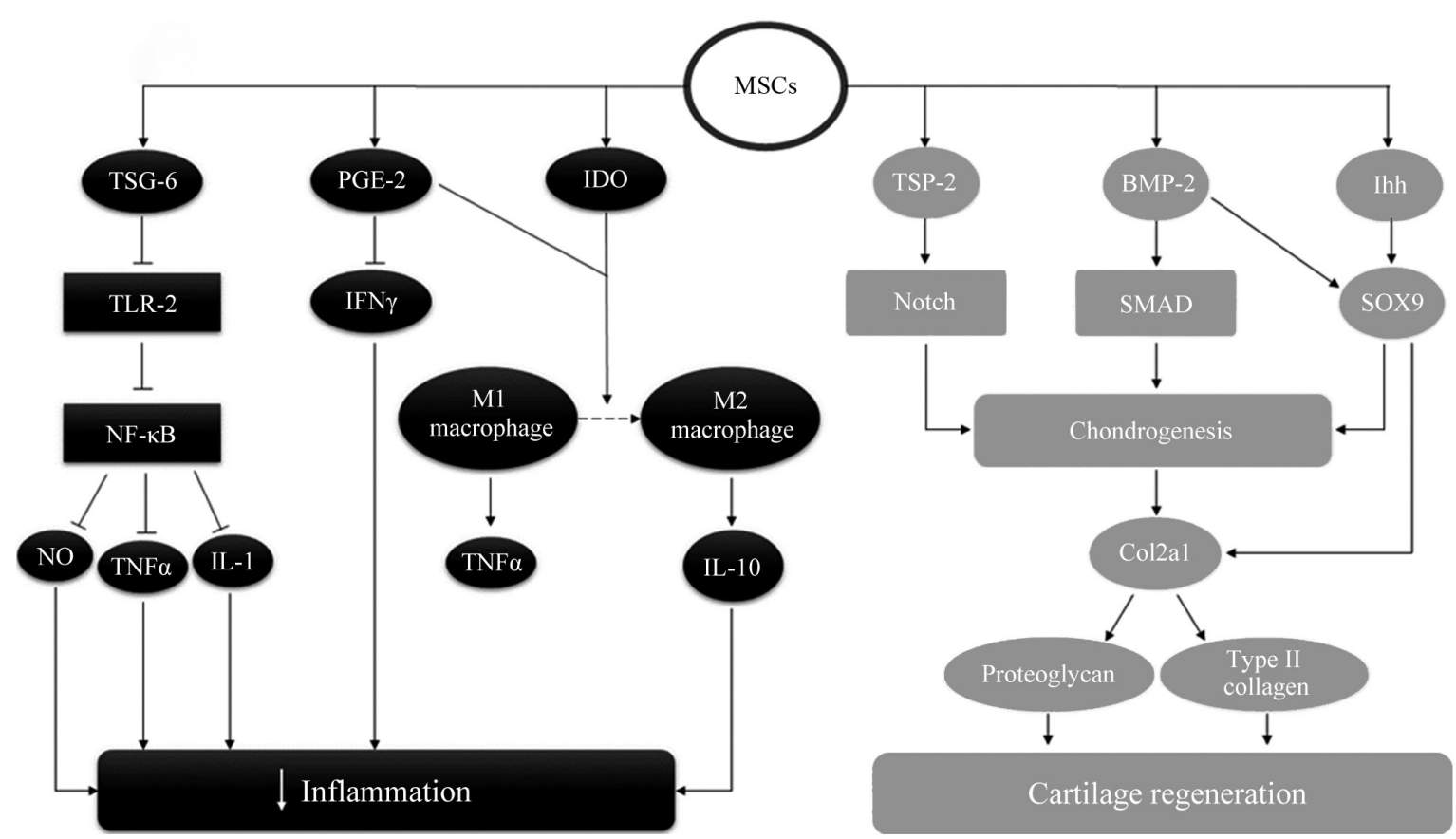

Figure 2. Summary of the likely mechanism by which MSCs exert their anti-inflammatory (black) and cartilage regeneration (grey) effects. Solid arrows indicate stimulation; dashed arrows indicate differentiation; flatheaded arrows indicate inhibition. MSC, mesenchymal stem cell; Col2a1, collagen type $2 \alpha 1$ chain; IDO, indoleamine 2,3-dioxygenase; NF- $\mathrm{kB}$, nuclear factor $\kappa$-light-chain-enhancer of activated B cells; NO, nitric oxide; PGE-2, prostaglandin E2; SOX9, SRY-box transcription factor 9; TLR-2, toll-like receptor-2; TNF, tumor necrosis factor; TSG-6, TNF $\alpha$-stimulated gene/protein 6; TSP-2, thrombospondin-2.

\section{Challenges involved in the use of MSC therapy for OA}

Despite the promising aspects for the use of MSCs clinically, this approach is considered relatively new and is surrounded by challenges involved in its use for OA, and these are discussed below.

Effects of the donor's health condition and age on stem cell properties. The differentiation potential and proliferation capacity of the MSCs are known to be affected by patients requiring autologous MSC therapy. Certain metabolic conditions, such as diabetes and obesity, can generate microenvironmental cues that predispose the differentiation potential of MSCs towards adipocyte differentiation rather than chondrocyte differentiation (126-128). Besides, the proliferative capacity of MSCs decreased with age (126).

Instability of chondrocyte-like phenotypes. One of the major challenges accompanying the use of MSCs for treatment of $\mathrm{OA}$ is the unsustainable cellular and hyaline cartilage phenotype of differentiated chondrocytes. Previous studies have documented the possible involvement of these cells in the development of heterotopic ossification, a process where bone formation occurs in non-skeletal tissues (129-132). These studies reported on the transient secretion of type II collagen from the MSCs, followed by the up-regulated expression of collagen type $\mathrm{X}$, matrix metalloproteinase and alkaline phosphatase activity, thus indicating a shift from the chondrogenic to a hypertrophic phenotype that precedes osteogenesis, a phenomenon that does not normally occur amongst the chondrocytes found in the hyaline cartilage in the joints.

Limited replicative lifespan. As mentioned earlier, the MSCs will enter a state of senescence whereby they lose their ability to proliferate. This is a double-edged characteristic, as it may lower the risk of malignant tumors, but limit the therapeutic use of stem cells. It was documented that the MSCs exhibited abnormalities in the morphology of the cells, such as enlargement, reduced expression of specific surface markers, and finally senescence as they reached higher passage numbers $(133,134)$. The entry into a state of senescence in MSCs was shown to affect the differential potential of the cells, the immunomodulation capability and their migratory ability (133). Although cryopreservation of MSCs can be used to address this issue, the process comes with its own challenges; a decrease in viability, colony forming units and integrin expression were observed after cryopreservation and thawing of the cells (135).

Technical challenges. MSC therapy requires highly skilled professionals, as the culturing of MSCs must be performed with utmost care to prevent contamination of the cells. Additionally, considerably more research is required in order to establish a clear protocol for the isolation, expansion, differentiation and pre-conditioning of MSCs, and to determine the appropriate concentration of MSCs for use in patients with OA.

Social. While stem cell therapy may offer an attractive option for treatment of currently uncurable diseases, the costs are currently considerably high, owing to the need to cover the cost of the individual harvesting, isolation, and expansion of cells in a sterile facility. Additionally, the increasing popularity of stem cell therapy has warranted the use widespread biobanking, and an increased access to the various highly multipotent stem cells, which could be at risk of exploitation. Hence, policies on biobanking of stem cells must be regulated to address the possible issues regarding its usage, control as well as patients' consent. 


\section{Conclusions}

The emergence of stem cell-based therapies has brought about novel avenues to address the, as of yet, unmet curative treatment for various degenerative disorders, including OA. The multipotency of the MSCs, along with its self-renewal and immunomodulatory properties, availability and ease of isolation highlight the potential use of MSCs for cellular therapeutic approaches in $\mathrm{OA}$, and promising results have been demonstrated in various pre-clinical and clinical trials. However, several challenges are involved in this process, and this requires standardized solutions before they can be recommended clinically. Efforts on investigating and establishing protocols to increase the stability of the chondrocyte-like phenotype of the MSCs is required to raise the success rates of MSC-based treatment in patients with OA, and to lower the cost. In addition, the appropriate concentration of stem cells for specific treatments, and the long-term follow-ups of patients with OA treated with MSCs should be performed to investigate the long-term safety and efficacy of MSC-based therapy.

\section{Acknowledgements}

Not applicable.

\section{Funding}

No funding was received.

\section{Availability of data and materials}

Not applicable.

\section{Authors' contributions}

SJQL and NKW both wrote and revised the article. Both authors read and approved the final manuscript. Data sharing is not applicable.

\section{Ethics approval and consent to participate}

Not applicable.

\section{Patient consent for publication}

Not applicable.

\section{Competing interests}

The authors declare that they have no competing interests.

\section{References}

1. National Clinical Guideline Centre (UK): Osteoarthritis-Care and Management in Adults. London: National Institute for Health and Care Excellence (UK), 2014.

2. James SL, Abate D, Hassen Abate K, Abay SM, Abbafati C, Abbasi N, Abbastabar H, Abd-Allah F, Abdela J, Abdelalim A, et al: Global, regional, and national incidence, prevalence, and years lived with disability for 354 diseases and injuries for 195 countries and territories, 1990-2017: A systematic analysis for the Global Burden of Disease Study 2017. Lancet 392: 1789-1858, 2018.
3. Blagojevic M, Jinks C, Jeffery A and Jordan KP: Risk factors for onset of osteoarthritis of the knee in older adults: A systemic review and meta-analysis. Osteoarthritis Cartilage 18: 24-33, 2010.

4. Loeser RF: Molecular mechanisms of cartilage destruction: Mechanics, inflammatory mediators, and aging collide. Arthritis Rheum 54: 1357-1360, 2006.

5. Ng HY, Alvin Lee KX and Shen KX: Articular cartilage: Structure, composition, injuries and repair. JSM Bone Jt Dis 1: $1010,2017$.

6. Ostrowska M, Maśliński W, Prochorec-Sobieszek M, Nieciecki M and Sudoł-Szopińska I: Cartilage and bone damage in rheumatoid arthritis. Reumatologia 56: 111-120, 2018.

7. Mahajan A, Verma S and Tandon V: Osteoarthritis. J Assoc Physicians India 53: 634-641, 2005.

8. Houard X, Goldring MB and Berenbaum F: Homeostatic mechanisms in articular cartilage and role of inflammation in osteoarthritis. Curr Rheumatol Rep 15: 375, 2013.

9. Gignac MAM, Irvin E, Cullen K, Van Eerd D, Beaton DE, Mahood Q, McLeod C and Backman CL: Men and women's occupational activities and the risk of developing osteoarthritis of the knee, hip, or hands: A systematic review and recommendations for future research. Arthritis Care Res (Hoboken) 72: 378-396, 2020.

10. Michael JW, Schlüter-Brust KU and Eysel P: The epidemiology, etiology, diagnosis, and treatment of osteoarthritis of the knee. Dtsch Arztebl Int 107: 152-162, 2010.

11. Helliwell P: Osteoarthritis and Paget's disease. Br J Rheumatol 34: 1061-1063, 1995.

12. Mora JC, Przkora R and Cruz-Almeida Y: Knee osteoarthritis: Pathophysiology and current treatment modalities. J Pain Res 11: 2189-2196, 2018.

13. de l'Escalopier N, Anract P and Biau D: Surgical treatments for osteoarthritis. Ann Phys Rehabil Med 59: 227-233, 2016.

14. Øiestad BE, Juhl CB, Eitzen I and Thorlund JB: Knee extensor muscle weakness is a risk factor for development of knee osteoarthritis. A systematic review and meta-analysis. Osteoarthritis Cartilage 23: 171-177, 2015

15. March LM and Bagga H: Epidemiology of osteoarthritis in Australia. Med J Aust 180: S6-S10, 2004.

16. Messier SP: Obesity and osteoarthritis: Disease genesis and nonpharmacologic weight management. Rheum Dis Clin North Am 34: 713-729, 2008.

17. Vincent KR and Vincent HK: Resistance exercise for knee osteoarthritis. PM R 4 (Suppl 5): S45-S52, 2012.

18. Rogers MW and Wilder FV: The effects of strength training among persons with hand osteoarthritis: A two-year follow-up study. J Hand Ther 20: 244-249; quiz 250, 2007.

19. Latham N and Liu CJ: Strength training in older adults: The benefits for osteoarthritis. Clin Geriatr Med 26: 445-459, 2010.

20. Aguiar GC, Rocha SG, da Silva Rezende GA, do Nascimento MR and Scalzo PL: Effects of resistance training in individuals with knee osteoarthritis. Fisioter Mov 29: 589-596, 2016.

21. Thoumie P, Marty M, Avouac B, Pallez A, Vaumousse A, Pipet LPT, Monroche A, Graveleau N, Bonnin A, Amor CB and Coudeyre E: Effect of unloading brace treatment on pain and function in patients with symptomatic knee osteoarthritis: The ROTOR randomized clinical trial. Sci Rep 8: 10519, 2018.

22. Chew KT, Lew HL, Date E and Fredericson M: Current evidence and clinical applications of therapeutic knee braces. Am J Phys Med Rehabil 86: 678-686, 2007.

23. Lee PY, Winfield TG, Harris SR, Storey E and Chandratreya A: Unloading knee brace is a cost-effective method to bridge and delay surgery in unicompartmental knee arthritis. BMJ Open Sport Exerc Med 2: e000195, 2017.

24. Ostrander RV, Leddon CE, Hackel JG, O'Grady CP and Roth CA: Efficacy of unloader bracing in reducing symptoms of knee osteoarthritis. Am J Orthop (Belle Mead NJ) 45: 306-311, 2016.

25. Wilson B, Rankin H and Barnes CL: Long-term results of an unloader brace in patients with unicompartmental knee osteoarthritis. Orthopedics 34: e334-e337, 2011.

26. Yu SP, Williams M, Eyles JP, Chen JS, Makovey J and Hunter DJ: Effectiveness of knee bracing in osteoarthritis: Pragmatic trial in a multidisciplinary clinic. Int J Rheum Dis 19: 279-286, 2016.

27. Squyer E, Stamper DL, Hamilton DT, Sabin JA and Leopold SS: Unloader knee braces for osteoarthritis: Do patients actually wear them? Clin Orthop Relat Res 471: 1982-1991, 2013.

28. Nejati P, Farzinmehr A and Moradi-Lakeh M: The effect of exercise therapy on knee osteoarthritis: A randomized clinical trial. Med J Islam Repub Iran 29: 186, 2015. 
29. Reid MC, Eccleston $\mathrm{C}$ and Pillemer K: Management of chronic pain in older adults. BMJ 350: h532, 2015.

30. Rönn K, Reischl N, Gautier E and Jacobi M: Current surgical treatment of knee osteoarthritis. Arthritis 2011: 454873, 2011.

31. Wang X, Wanyan P, Wang JM, Tian JH, Hu L, Shen XP and Yang KH: A randomized, controlled trial to assess the efficacy of arthroscopic debridement in combination with oral medication versus oral medication in patients with gouty knee arthritis. Indian J Surg 77 (Suppl 2): S628-S634, 2015

32. Kirkley A, Birmingham TB, Litchfield RB, Giffin JR, Willits KR, Wong CJ, Feagan BG, Donner A, Griffin SH, D'Ascanio LM, et al: A randomized trial of arthroscopic surgery for osteoarthritis of the knee. N Engl J Med 359: 1097-1107, 2008.

33. Moseley JB, O'Malley K, Petersen NJ, Menke TJ, Brody BA, Kuykendall DH, Hollingsworth JC, Ashton CM and Wray NP. A controlled trial of arthroscopic surgery for osteoarthritis of the knee. N Engl J Med 347: 81-88, 2002.

34. Choi HG, Kwon BC, Kim JI and Lee JK: Total knee arthroplasty reduces the risk of mortality in osteoarthritis patients up to 12 years: A Korean national cohort longitudinal follow-up study. J Orthop Surg (Hong Kong) 28: 2309499020902589, 2020.

35. Rajabzadeh N, Fathi E and Farahzadi R: Stem cell-based regenerative medicine. Stem Cell Investig 6: 19,2019.

36. Landry DW and Zucker HA: Embryonic death and the creation of human embryonic stem cells. J Clin Invest 114: 1184-1186, 2004

37. Ede V and Obeagu EI: Ethical issues in human embryonic stem cell research: A christian perspective. Int J Med Sci Dent Res 1: 8-14, 2019.

38. Lo B and Parham L: Ethical issues in stem cell research. Endocr Rev 30: 204-213, 2009.

39. Takahashi K and Yamanaka S: Induction of pluripotent stem cells from mouse embryonic and adult fibroblast cultures by defined factors. Cell 126: 663-676, 2006.

40. Shi Y, Inoue H, Wu JC and Yamanaka S: Induced pluripotent stem cell technology: A decade of progress. Nat Rev Drug Discov 16: 115-130, 2017.

41. Takahashi K, Tanabe K, Ohnuki M, Narita M, Ichisaka T, Tomoda $\mathrm{K}$ and Yamanaka S: Induction of pluripotent stem cells from adult human fibroblasts by defined factors. Cell 131: $861-872,2007$

42. Gutierrez-Aranda I, Ramos-Mejia V, Bueno C, Munoz-Lopez M Real PJ, Mácia A, Sanchez L, Ligero G, Garcia-Parez JL and Menendez P: Human induced pluripotent stem cells develop teratoma more efficiently and faster than human embryonic stem cells regardless the site of injection. Stem Cells 28: 1568-1570, 2010.

43. Zhang M, Wang L, An K, Cai J, Li G, Yang C, Liu H, Du F, Han X, Zhang Z, et al: Lower genomic stability of induced pluripotent stem cells reflects increased non-homologous end joining. Cancer Commun (Lond) 38: 49, 2018.

44. Christensen $\mathrm{R}$ and Serakinci N: Adult Stem Cells. In: Encyclopedia of Cancer. Springer, Heidelberg, pp1-5, 2015.

45. Centeno C, Markle J, Dodson E, Stemper I, Williams CJ, Hyzy M, Ichim $\mathrm{T}$ and Freeman M: Treatment of lumbar degenerative disc disease-associated radicular pain with culture-expanded autologous mesenchymal stem cells: A pilot study on safety and efficacy. J Transl Med 15: 197, 2017.

46. Berry JD, Cudkowicz ME, Windebank AJ, Staff NP, Owegi M, Nicholson K, McKenna-Yasek D, Levy YS, Abramov N, Kaspi H, et al: NurOwn, phase 2, randomized, clinical trial in patients with ALS: Safety, clinical, and biomarker results. Neurology 93: e2294-e2305, 2019.

47. Riecke J, Johns KM, Cai C, Vahidy FS, Parsha K, Furr-Stimming E, Schiess M and Savitz SI: A meta-analysis of mesenchymal stem cells in animal models of Parkinson's disease. Stem Cells Dev 24: 2082-2090, 2015

48. Ng AP and Alexander WS: Haematopoietic stem cells: Past, present and future. Cell Death Discov 3: 17002, 2017.

49. Yamamoto R, Wilkinson AC and Nakauchi H: Changing concepts in hematopoietic stem cells. Science 362: 895-896, 2018.

50. Domen J, Wagers A and Weissman IL: Bone marrow (Hematopoietic) stem cells. Stem Cell Information: The Nationa Institutes of Health resource for stem cell research: 13-34, 2006.

51. Morgan RA, Gray D, Lomova A and Kohn DB: Hematopoietic stem cell gene therapy: Progress and lessons learned. Cell Stem Cell 21: 574-590, 2017.

52. Taylor M, Khan S, Stapleton M, Wang J, Chen J, Wynn R, Yabe H, Chinen Y, Boelens JJ, Mason RW, et al: Hematopoietic stem cell transplantation for mucopolysaccharidoses: Past, present, and future. Biol Blood Marrow Transplant 25: e226-e246, 2019.
53. Walters MC: Update of hematopoietic cell transplantation for sickle cell disease. Curr Opin Hematol 22: 227-233, 2015.

54. Abdelmoaty N, Alattar E, Ahmed K, Ibrahim Y and Darwish B: Regenerative power of autologous peripheral blood stem cell injection in knee osteoarthritis by a non-invasive approach-MRI Study. Ann Rheum Dis 73: 1066, 2014.

55. U.S Food and Drug Administration: Approved Cellular and Gene Therapy Products, 2021.

56. Prockop DJ: Marrow stromal cells as stem cells for nonhematopoietic tissues. Science 276: 71-74, 1997.

57. Makino S, Fukuda K, Miyoshi S, Konishi F, Kodama H, Pan J, Sano M, Takahashi T, Hori S, Abe H, et al: Cardiomyocytes can be generated from marrow stromal cells in vitro. J Clin Invest 103: 697-705, 1999.

58. Wakitani S, Saito T and Caplan AI: Myogenic cells derived from rat bone marrow mesenchymal stem cells exposed to 5-azacytidine. Muscle Nerve 18: 1417-1426, 1995

59. Nuttall ME, Patton AJ, Olivera DL, Nadeau DP and Gowen M Human trabecular bone cells are able to express both osteoblastic and adipocytic phenotype: Implications for osteopenic disorders. J Bone Miner Res 13: 371-382, 1998.

60. Pittenger MF, Mackay AM, Beck SC, Jaiswal RK, Douglas R, Mosca JD, Moorman MA, Simonetti DW, Craig S and Marshak DR: Multilineage potential of adult human mesenchymal stem cells. Science 284: 143-147, 1999.

61. Bianco P, Robey PG and Simmons PJ: Mesenchymal stem cells: Revisiting history, concepts, and assays. Cell Stem Cell 2: 313-319, 2008.

62. Roufosse CA, Direkze NC, Otto WR and Wright NA: Circulating mesenchymal stem cells. Int J Biochem Cell Biol 36: 585-597, 2004.

63. Lindroos B, Suuronen R and Miettinen S: The potential of adipose stem cells in regenerative medicine. Stem Cell Rev Rep 7: 269-291, 2011.

64. Erices A, Conget P and Minguell JJ: Mesenchymal progenitor cells in human umbilical cord blood. Br J Haematol 109: 235-242, 2000.

65. Gronthos S, Mankani M, Brahim J, Robey PG and Shi S: Postnatal human dental pulp stem cells (DPSCs) in vitro and in vivo. Proc Natl Acad Sci USA 97: 13625-13630, 2000.

66. Haniffa MA, Wang XN, Holtick U, Rae M, Isaacs JD, Dickinson AM, Hilkens CM and Collin MP: Adult human fibroblasts are potent immunoregulatory cells and functionally equivalent to mesenchymal stem cells. J Immunol 179: 1595-1604, 2007

67. Sessarego N, Parodi A, Podesta M, Benvenuto F, Mogni M, Raviolo V, Lituania M, Kunkl A, Ferlazzo G, Bricarelli FD, et al: Multipotent mesenchymal stromal cells from amniotic fluid: Solid perspectives for clinical application. Haematologica 93: 339-346, 2008.

68. Dominici M, Le Blanc K, Mueller I, Slaper-Cortenbach I, Marini F, Krause D, Deans R, Keating A, Prockop DJ and Horwitz E: Minimal criteria for defining multipotent mesenchymal stromal cells. The International society for cellular therapy position statement. Cytotherapy 8: 315-317, 2006.

69. Gianakos AL, Sun L, Patel JN, Adams DM and Liporace FA Clinical application of concentrated bone marrow aspirate in orthopaedics: A systematic review. World J Orthop 8: 491-506, 2017.

70. Mohamed-Ahmed S, Fristad I, Lie SA, Suliman S, Mustafa K, Vindenes $\mathrm{H}$ and Idris SB: Adipose-derived and bone marrow mesenchymal stem cells: A donor-matched comparison. Stem Cell Res Ther 9: 168, 2018

71. Gabr MM, Zakaria MM, Refaie AF, Abdel-Rahman EA, Reda AM, Ali SS, Khater SM, Ashamallah SA, Ismail AM, Ismail HEA, et al: From human mesenchymal stem cells to insulin-producing cells: Comparison between bone marrow- and adipose tissue-derived cells. Biomed Res Int 2017: 3854232 , 2017.

72. da Silva Meirelles L, Chagastelles PC and Nardi NB: Mesenchymal stem cells reside in virtually all post-natal organs and tissues. J Cell Sci 119: 2204-2213, 2006.

73. Crisan M, Yap S, Casteilla L, Chen CW, Corselli M, Park TS, Andriolo G, Sun B, Zheng B, Zhang L, et al: A perivascular origin for mesenchymal stem cells in multiple human organs. Cell Stem Cell 3: 301-313, 2008.

74. Orozco L, Munar A, Soler R, Alberca M, Soler F, Huguet M, Sentís J, Sánchez A and García-Sancho J: Treatment of knee osteoarthritis with autologous mesenchymal stem cells: A pilot study. Transplantation 95: 1535-1541, 2013. 
75. Lamo-Espinosa JM, Mora G, Blanco JF, Granero-Moltó F, Nuñez-Córdoba JM, Sánchez-Echenique C, Bondía JM, Aquerreta JD, Andreu EJ, Ornilla E, et al: Intra-articular injection of two different doses of autologous bone marrow mesenchymal stem cells versus hyaluronic acid in the treatment of knee osteoarthritis: Multicenter randomized controlled clinical trial (phase I/II). J Transl Med 14: 246, 2016.

76. Garay-Mendoza D, Villarreal-Martínez L, Garza-Bedolla A, Pérez-Garza DM, Acosta-Olivo C, Vilchez-Cavazos F, Diaz-Hutchinson C, Gómez-Almaguer D, Jaime-Pérez JC and Mancías-Guerra C: The effect of intra-articular injection of autologous bone marrow stem cells on pain and knee function in patients with osteoarthritis. Int J Rheum Dis 21: 140-147, 2018.

77. Vega A, Martín-Ferrero MA, Del Canto F, Alberca M, García V, Munar A, Orozco L, Soler R, Fuertes JJ, Huguet M, et al: Treatment of knee osteoarthritis with allogeneic bone marrow mesenchymal stem cells: A randomized controlled trial. Transplantation 99: 1681-1690, 2015.

78. Shadmanfar S, Labibzadeh N, Emadedin M, Jaroughi N, Azimian V, Mardpour S, Kakroodi FA, Bolurieh T, Hosseini SE, Chehrazi M, et al: Intra-articular knee implantation of autologous bone marrow-derived mesenchymal stromal cells in rheumatoid arthritis patients with knee involvement: Results of a randomized, triple-blind, placebo-controlled phase 1/2 clinical trial. Cytotherapy 20: 499-506, 2018.

79. Al-Najar M, Khalil H, Al-Ajlouni J, Al-Antary E, Hamdan M, Rahmeh R, Alhattab D, Samara O, Yasin M, Abdullah AA, et al: Intra-articular injection of expanded autologous bone marrow mesenchymal cells in moderate and severe knee osteoarthritis is safe: A phase I/II study. J Orthop Surg Res 12: 190, 2017.

80. Anz AW, Hubbard R, Rendos NK, Everts PA, Andrews JR and Hackel JG: Bone marrow aspirate concentrate is equivalent to platelet-rich plasma for the treatment of knee osteoarthritis at 1 year: A prospective, randomized trial. Orthop J Sports Med 2: 2325967119900958, 2020

81. Chahal J, Gómez-Aristizábal A, Shestopaloff K, Bhatt S, Chaboureau A, Fazio A, Chisholm J, Weston A, Chiovitti J, Keating A, et al: Bone marrow mesenchymal stromal cell treatment in patients with osteoarthritis results in overall improvement in pain and symptoms and reduces synovial inflammation. Stem Cells Transl Med 8: 746-757, 2019.

82. Zuk PA, Zhu M, Mizuno H, Huang J, Futrell JW, Katz AJ, Benhaim P, Lorenz HP and Hedrick MH: Multilineage cells from human adipose tissue: Implications for cell-based therapies 2. Tissue Eng 7: 211-228, 2001.

83. Zuk PA, Zhu M, Ashjian P, De Ugarte DA, Huang JI, Mizuno H, Alfonso ZC, Fraser JK, Benhaim P and Hedrick MH: Human adipose tissue is a source of multipotent stem cells. Raff M (ed). Mol Biol Cell 13: 4279-4295, 2002.

84. Coughlin RP, Oldweiler A, Mickelson DT and Moorman CT III: Adipose-derived stem cell transplant technique for degenerative joint disease. Arthrosc Tech 6: e1761-e1766, 2017.

85. Freitag J, Bates D, Wickham J, Shah K, Huguenin L, Tenen A, Paterson K and Boyd R: Adipose-derived mesenchymal stem cell therapy in the treatment of knee osteoarthritis: A randomized controlled trial. Regen Med 14: 213-230, 2019.

86. De Ugarte DA, Alfonso Z, Zuk PA, Elbarbary A, Zhu M, Ashjian P, Benhaim P, Hedrick MH and Fraser JK: Differential expression of stem cell mobilization-associated molecules on multi-lineage cells from adipose tissue and bone marrow. Immunol Lett 89: 267-270, 2003.

87. Yang ZX, Han ZB, Ji YR, Wang YW, Liang L, Chi Y, Yang SG, Li LN, Luo WF, Li JP, et al: CD106 identifies a subpopulation of mesenchymal stem cells with unique immunomodulatory properties. PLoS One 8: e59354, 2013.

88. Krampera M, Marconi S, Pasini A, Galiè M, Rigotti G, Mosna F, Tinelli M, Lovato L, Anghileri E, Andreini A, et al: Induction of neural-like differentiation in human mesenchymal stem cells derived from bone marrow, fat, spleen and thymus. Bone 40 : 382-390, 2007.

89. Kennea NL, Waddington SN, Chan J, O'Donoghue K, Yeung D, Taylor DL, Al-Allaf FA, Pirianov G, Themis M, Edwards AD, et al: Differentiation of human fetal mesenchyma stem cells into cells with an oligodendrocyte phenotype. Cell Cycle 8: 1069-1079, 2009.

90. Shah S, Yin PT, Uehara TM, Chueng ST, Yang L and Lee KB Guiding stem cell differentiation into oligodendrocytes using graphene-nanofiber hybrid scaffolds. Adv Mater 26: 3673-3680, 2014
91. Steffenhagen C, Dechant FX, Oberbauer E, Furtner T, Weidner N, Küry P, Aigner L and Rivera FJ: Mesenchymal stem cells prime proliferating adult neural progenitors toward an oligodendrocyte fate. Stem Cells Dev 21: 1838-1851, 2012.

92. Allahverdi A, Abroun S, Jafarian A, Soleimani M, Taghikhani M and Eskandari F: Differentiation of human mesenchymal stem cells into insulin producing cells by using a lentiviral vector carrying PDX1. Cell J 17: 231-242, 2015.

93. Chen LB, Jiang XB and Yang L: Differentiation of rat marrow mesenchymal stem cells into pancreatic islet beta-cells. World J Gastroenterol 10: 3016-3020, 2004

94. Singh A, Singh A and Sen D: Mesenchymal stem cells in cardiac regeneration: A detailed progress report of the last 6 years (2010-2015). Stem Cell Res Ther 7: 82, 2016

95. Solis MA, Moreno Velásquez I, Correa R and Huang LLH: Stem cells as a potential therapy for diabetes mellitus: A call-to-action in Latin America. Diabetol Metab Syndr 11: 20, 2019.

96. Sun R, Li X, Liu M, Zeng Y, Chen S and Zhang P: Advances in stem cell therapy for cardiovascular disease (Review). Int J Mol Med 38: 23-29, 2016

97. Terashvili M and Bosnjak ZJ: Stem cell therapies in cardiovascular disease. J Cardiothorac Vasc Anesth 33: 209-222, 2019

98. Paspaliaris V and Kolios G: Stem cells in osteoporosis: From biology to new therapeutic approaches. Stem Cells Int 2019: $1730978,2019$.

99. Mercado-Sáenz S, Ruiz-Gómez MJ, Morales-Moreno F and Martínez-Morillo M: Cellular aging: Theories and technological influence. Brazilian Arch Biol Technol 53: 1319-1332, 2010.

100. Shay JW and Wright WE: Role of telomeres and telomerase in cancer. Semin Cancer Biol 21: 349-353, 2011.

101. Keating A: Mesenchymal stromal cells: New directions. Cell Stem Cell 10: 709-716, 2012

102. Le Blanc K and Mougiakakos D: Multipotent mesenchymal stromal cells and the innate immune system. Nat Rev Immunol 12: 383-396, 2012

103. Prockop DJ and Oh JY: Mesenchymal stem/stromal cells (MSCs): Role as guardians of inflammation. Mol Ther 20: 14-20, 2012.

104. Ryan JM, Barry FP, Murphy JM and Mahon BP: Mesenchymal stem cells avoid allogeneic rejection. J Inflamm (Lond) 2: 8, 2005.

105. Klyushnenkova E, Mosca JD, Zernetkina V, Majumdar MK, Beggs KJ, Simonetti DW, Deans RJ and McIntosh KR: T cell responses to allogeneic human mesenchymal stem cells: Immunogenicity, tolerance, and suppression. J Biomed Sci 12: 47-57, 2005

106. Di Nicola M, Carlo-Stella C, Magni M, Milanesi M, Longoni PD, Matteucci P, Grisanti S and Gianni AM: Human bone marrow stromal cells suppress T-lymphocyte proliferation induced by cellular or nonspecific mitogenic stimuli. Blood 99: 3838-3843, 2002

107. Tse WT, Pendleton JD, Beyer WM, Egalka MC and Guinan EC: Suppression of allogeneic T-cell proliferation by human marrow stromal cells: Implications in transplantation. Transplantation 75 389-397, 2003

108. Lee H, Shamy GA, Elkabetz Y, Schofield CM, Harrsion NL, Panagiotakos G, Socci ND, Tabar V and Studer L: Directed differentiation and transplantation of human embryonic stem cell-derived motoneurons. Stem Cells 25: 1931-1939, 2007.

109. Su W, Zhou M, Zheng Y, Fan Y, Wang L, Han Z, Kong D, Zhao RC, Wu JC, Xiang R and Li Z: Bioluminescence reporter gene imaging characterize human embryonic stem cell-derived teratoma formation. J Cell Biochem 112: 840-848, 2011.

110. Aggarwal S and Pittenger MF: Human mesenchymal stem cells modulate allogeneic immune cell responses. Blood 105 1816-1822, 2005.

111. $\mathrm{Li} \mathrm{H}$ and $\mathrm{Fu} \mathrm{X}$ : Mechanisms of action of mesenchymal stem cells in cutaneous wound repair and regeneration. Cell Tissue Res 348: 371-377, 2012

112. Maxson S, Lopez EA, Yoo D, Danilkovitch-Miagkova A and Leroux MA: Concise review: Role of mesenchymal stem cells in wound repair. Stem Cells Transl Med 1: 142-149, 2012.

113. Williams CG, Kim TK, Taboas A, Malik A, Manson P and Elisseeff J: In vitro chondrogenesis of bone marrow-derived mesenchymal stem cells in a photopolymerizing hydrogel. Tissue Eng 9: 679-688, 2003.

114. Zhang W, Ge W, Li C, You S, Liao L, Han Q, Deng W and Zhao RC: Effects of mesenchymal stem cells on differentiation, maturation, and function of human monocyte-derived dendritic cells. Stem Cells Dev 13: 263-271, 2004 
115. Choi H, Lee RH, Bazhanov N, Oh JY and Prockop DJ: Anti-inflammatory protein TSG-6 secreted by activated MSCs attenuates zymosan-induced mouse peritonitis by decreasing TLR2/NF- $\kappa \mathrm{B}$ signaling in resident macrophages. Blood 118: 330-338, 2011.

116. Németh K, Leelahavanichkul A, Yuen PS, Mayer B, Parmelee A, Doi K, Robey PG, Leelahavanichkul K, Koller BH, Brown JM, et al: Bone marrow stromal cells attenuate sepsis via prostaglandin $\mathrm{E}(2)$-dependent reprogramming of host macrophages to increase their interleukin-10 production. Nat Med 15: 42-49, 2009

117. François M, Romieu-Mourez R,LiM and Galipeau J: Human MSC suppression correlates with cytokine induction of indoleamine 2,3-dioxygenase and bystander M2 macrophage differentiation. Mol Ther 20: 187-195, 2012.

118. Shapiro SA, Kazmerchak SE, Heckman MG, Zubair AC and O'Connor MI: A prospective, single-blind, placebo-controlled trial of bone marrow aspirate concentrate for knee osteoarthritis. Am J Sports Med 45: 82-90, 2017.

119. Kanaya A, Deie M, Adachi N, Nishimori M, Yanada S and Ochi M: Intra-articular injection of mesenchymal stromal cells in partially torn anterior cruciate ligaments in a rat model. Arthroscopy 23: 610-617, 2007.

120. Eseonu OI and De Bari C: Homing of mesenchymal stem cells: Mechanistic or stochastic? Implications for targeted delivery in arthritis. Rheumatology (Oxford) 54: 210-218, 2015.

121. Horie M, Choi H, Lee RH, Reger RL, Ylostalo J, Muneta T, Sekiya I and Prockop DJ: Intra-articular injection of human mesenchymal stem cells (MSCs) promote rat meniscal regeneration by being activated to express Indian hedgehog that enhances expression of type II collagen. Osteoarthritis Cartilage 20: 1197-1207, 2012.

122. Jeong SY, Ha J, Lee M, Jin HJ, Kim DH, Choi SJ, Oh W, Yang YS, Kim JS, Kim BG, et al: Autocrine action of thrombospondin-2 determines the chondrogenic differentiation potential and suppresses hypertrophic maturation of human umbilical cord blood-derived mesenchymal stem cells. Stem Cells 33: 3291-3303, 2015.

123. Scarfî S: Use of bone morphogenetic proteins in mesenchymal stem cell stimulation of cartilage and bone repair. World J Stem Cells 8: 1-12, 2016.

124. Oliver KS, Bayes M, Crane D and Pathikonda C: Clinical outcome of bone marrow concentrate in knee osteoarthritis. J Prolotherapy 7: 937-946, 2015

125. Jo CH, Lee YG, Shin WH, Kim H, Chai JW, Jeong EC, Kim JE, Shim H, Shin JS, Shin IS, et al: Intra-articular injection of mesenchymal stem cells for the treatment of osteoarthritis of the knee: A proof-of-concept clinical trial. Stem Cells 32: 1254-1266, 2014

126. Dexheimer V, Mueller S, Braatz F and Richter W: Reduced reactivation from dormancy but maintained lineage choice of human mesenchymal stem cells with donor age. PLoS One 6: e22980, 2011.

127. Ferone A and Messina G: Sera of overweight patients alter adipogenesis and osteogenesis of bone marrow mesenchymal stromal cells, a phenomenon that also persists in weight loss individuals. J Stem Cell Res Ther 6: 1000347, 2016.

128. Mansilla E, Díaz Aquino V, Zambn D, Marin GH, Mártire K, Roque G, Ichim T, Riordan NH, Patel A, Sturla F, et al: Could metabolic syndrome, lipodystrophy, and aging be mesenchymal stem cell exhaustion syndromes? Stem Cells Int 2011: 943216, 2011.

129. Johnstone B, Hering TM, Caplan AI, Goldberg VM and Yoo JU: In vitro chondrogenesis of bone marrow-derived mesenchymal progenitor cells. Exp Cell Res 238: 265-272, 1998.

130. Tatebe M, Nakamura R, Kagami H, Okada K and Ueda M: Differentiation of transplanted mesenchymal stem cells in a large osteochondral defect in rabbit. Cytotherapy 7: 520-530, 2005 .
131. Pelttari K, Winter A, Steck E, Goetzke K, Hennig T, Ochs BG, Aigner T and Richter W: Premature induction of hypertrophy during in vitro chondrogenesis of human mesenchymal stem cells correlates with calcification and vascular invasion after ectopic transplantation in SCID mice. Arthritis Rheum 54: 3254-3266, 2006.

132. Mackay AM, Beck SC, Murphy JM, Barry FP, Chichester CO and Pittenger MF: Chondrogenic differentiation of cultured human mesenchymal stem cells from marrow. Tissue Eng 4: 415-428, 1998

133. Turinetto V, Vitale E and Giachino C: Senescence in human mesenchymal stem cells: Functional changes and implications in stem cell-based therapy. Int J Mol Sci 17: 1164, 2016.

134. Gu Y, Li T, Ding Y, Sun L, Tu T, Zhu W, Hu J and Sun X: Changes in mesenchymal stem cells following long-term culture in vitro. Mol Med Rep 13: 5207-5215, 2016.

135. Irioda AC, Cassilha R, Zocche L, Francisco JC, Cunha RC, Ferreira PE, Guarita-Souza LC, Ferreira RJ, Mogharbel BF, Garikipati VN, et al: Human adipose-derived mesenchymal stem cells cryopreservation and thawing decrease $\alpha 4$-Integrin expression. Stem Cells Int 2016: 2562718, 2016.

136. Bastos R, Mathias M, Andrade R, Bastos R, Balduino A, Schott V, Rodeo S and Espregueira-Mendes J: Intra-articular injections of expanded mesenchymal stem cells with and without addition of platelet-rich plasma are safe and effective for knee osteoarthritis. Knee Surg Sports Traumatol Arthrosc 11: 3342-3350, 2018.

137. Bastos R, Mathias M, Andrade R, Amaral RJFC, Schott V, Balduino A, Bastos R, Miguel Oliveira J, Reis RL, Rodeo S and Espregueira-Mendes J: Intra-articularinjection of culture-expanded mesenchymal stem cells with or without addition of platelet-rich plasma is effective in decreasing pain and symptoms in knee osteoarthritis: A controlled, double-blind clinical trial. Knee Surg Sports Traumatol Arthrosc 28: 1989-1999, 2020.

138. Emadedin M, Labibzadeh N, Liastani MG, Karimi A, Jaroughi N, Bolurieh T, Hosseini SE, Baharvand $\mathrm{H}$ and Aghdami N: Intra-articular implantation of autologous bone marrow-derived mesenchymal stromal cells to treat knee osteoarthritis: A randomized, triple-blind, placebo-controlled phase 1/2 clinical trial. Cytotherapy 20: 1238-1246, 2018.

139. Hernigou P, Auregan JC, Dubory A, Flouzat-Lachaniette $\mathrm{CH}$, Chevallier N and Rouard H: Subchondral stem cell therapy versus contralateral total knee arthroplasty for osteoarthritis following secondary osteonecrosis of the knee. Int Orthop 42: 2563-2571, 2018.

140. Gupta PK, Chullikana A, Rengasamy M, Shetty N, Pandey V, Agarwal V, Wagh SY, Vellotare PK, Damodaran D, Viswanathan P, et al: Efficacy and safety of adult human bone marrow-derived, cultured, pooled, allogeneic mesenchymal stromal cells $\left(\right.$ Stempeucel $\left.{ }^{\circledR}\right)$ : Preclinical and clinical trial in osteoarthritis of the knee joint. Arthritis Res Ther 18: 301, 2016.

141. Song Y, Du H, Dai C, Zhang L, Li S, Hunter DJ, Lu L and Bao C: Human adipose-derived mesenchymal stem cells for osteoarthritis: A pilot study with long-term follow-up and repeated injections. Regen Med 13: 295-307, 2018.

142. Lee WS, Kim HJ, Kim KI, Kim GB and Jin W: Intra-Articular injection of autologous adipose tissue-derived mesenchymal stem cells for the treatment of knee osteoarthritis: A phase IIb, randomized, placebo-controlled clinical trial. Stem Cells Transl Med 8: 504-511, 2019.

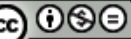

This work is licensed under a Creative Commons Attribution-NonCommercial-NoDerivatives 4.0 International (CC BY-NC-ND 4.0) License. 